\title{
PENGEMBANGAN DESAIN WORKSTATION UNTUK PENJAHIT BUSANA DENGAN AREA TERBATAS
}

\author{
Ni'matul Isnaini \\ Mahasiswa Program Studi Desain Produk, Jurusan Desain, \\ Institut Teknologi Adhi Tama Surabaya \\ e-mail: nimatulisnainy@gmail.com \\ Faza Wahmuda \\ Staf Pengajar Program Studi Desain Produk, Jurusan Desain, \\ Institut Teknologi Adhi Tama Surabaya \\ e-mail: faza.despro@itats.ac.id
}

\begin{abstract}
Abstrak
Usaha menjahit adalah usaha untuk mengubah tekstil menjadi pakaian jadi yang bisa digunakan konsumen. Terdapat banyak peralatan dan perlengkapan yang menunjang pekerjaan tersebut seperti benang, jarum, kancing, gunting, dan lain sebagainya, namun tidak memiliki tempat tersendiri sehingga penjahit merasa sedikit kesulitan saat mencari peralatan tersebut. Kemudian tempat untuk memotong pola, menjahit, dan setrika merupakan tempat yang berbeda sehingga penjahit harus berpindah tempat saat melakukan aktivitas tersebut. Dengan permasalahan diatas maka dibutuhkan fasilitas berupa workstation yang memiliki banyak fungsi, serta dilengkapi dengan penyimpanan semua peralatan dalam menjahit. Metode yang digunakan dalam pencarian data adalah mix metode, yaitu metode penelitian yang menggunakan pendekatan kualitatif (metode penelitian berdasarkan observasi dan wawancara secara intensif) dan kuantitatif (metode penelitian berdasarkan hasil kuesioner yang akan menjadi data pendukung dalam penelitian). Pada observasi dilakukan pada dua tempat di area Surabaya dan Sidoarjo kemudian analisis menggunakan analisis kebutuhan kerja, analisis kebutuhan penyimpanan, analisis dimensi penyimpanan, analisis dimensi area kerja, analisis layout area kerja, analisis penempatan, analisis material, analisis finishing, analisis sistem, analisis bentuk, dan analisis warna. Kemudian didapatkan hasil sintesa desain, konsep desain, lima alternatif desain dan ditutup dengan kesimpulan dan saran.
\end{abstract}

Kata kunci : desain, workstation, penjahit 
Ni'matul Isnaini, Faza Wahmuda, Pengembangan Desain Worksation Untuk Penjahit

Busana Dengan Area Terbatas

Abstract

Sewing project is a project to change textile material into clothes that can be worn by the consumers. There are many tools and equipment that support this job such as yarn, needle, button, scissors, etc. however, they don't have special place so the tailor gets difficulty when look for them. Besides that, the places to cut the pattern, to sew and to iron are different so the tailor has to move to other place when does those activities. By seeing that case, it needs a facility like a workstation that has many functions and be equipped by all sewing tools storage. The method that is used in searching data is mix method, means a research method using qualitative approach (research method based on observation and intensive interview) and quantitative (research method based on the result of questioners that can be support data in a research). The observations were made at two places in the area of Surabaya and Sidoarjo. In the step of analysis, it uses work need analysis, storage need analysis, storage dimension analysis, work area dimension analysis, work area layout analysis, placement analysis, material analysis, finishing analysis, system analysis, shape analysis, and colour analysis. Next, it will get the result of design synthesis, design concept, five alternative designs and ended by conclusion and advice.

Keywords : design, workstation, tailor

\section{Latar Belakang}

Persaingan bisnis pada bidang fashion sangat ketat terutama pada bidang busana, usaha busana merupakan suatu bisnis yang berkembang pesat dari tahun ketahun, hal ini terlihat dari tingginya permintaan konsumen yang akhirnya membuat banyak usaha di bidang busana, salah satu yang banyak ditemukan yaitu penjahit busana. Usaha menjahit adalah usaha untuk mengubah tekstil menjadi pakaian jadi yang bisa digunakan konsumen. Persiapan yang diperlukan di sini adalah kemampuan menterjemahkan keinginan konsumen untuk membuat pakaian yang sesuai seleranya. Hal itu dikarenakan orang sering menyukai model pakaian di suatu toko namun tidak terdapat ukuran yang sesuai dengan ukuran tubuh, selain itu banyak orang tidak ingin mengenakan pakaian yang banyak dipakai oleh orang lain. Oleh karena itu mereka berlomba-lomba mencari jasa penjahit yang dapat mengerjakan pakaian sesuai dengan keinginan mereka.

Terdapat beberapa usaha penjahit busana khususnya di daerah Surabaya dan Sidoarjo, ada yang perorangan maupun berkelompok. Para penjahit masih bekerja dengan menggunakan workstation yang 6

sederhana yang hanya dapat memuat mesin jahit dan sedikit ruang untuk pemotongan pola. Terdapat banyak peralatan dan perlengkapan yang menunjang pekerjaan tersebut seperti benang, jarum, kancing, gunting, dan lain sebagainya. Peralatan dan perlengkapan tersebut tidak memiliki tempat tersendiri sehingga penjahit merasa kesulitan saat mencari peralatan tersebut. Kemudian tempat untuk memotong pola, menjahit, dan setrika merupakan tempat yang berbeda sehingga penjahit harus berpindah tempat saat melakukan aktivitas tersebut.

\section{Tujuan Perancangan}

Tujuan dari penelitian ini adalah mendesain sebuah workstation yang tidak hanya berfungsi untuk menjahit saja, antara lain :

- Pembuatan pola pada kain

- Meja setrika

- Penyimpanan peralatan dan perlengkapan untuk menjahit seperti jarum, benang, resleting, dan kancing. 
Vol. 7, No. 2, April 2020

III. Metode Perancangan

Proses perancangan Desain Redesain Workstation untuk Penjahit Busana ini menggunakan Metode penelitian kombinasi (mixed methods) dari metode penelitian kualitatif dan metode penelitian kuantitatif. Metode penelitian kualitatif dilakukan dengan wawancara secara intensif. Peneliti ikut berpartisipasi dilapangan, mencatat secara hati-hati, melakukan reflektif terhadap berbagai dokumen yang ditemukan dilapangan dan data kuantitatif didapatkan dari hasil kuesioner, yang akan menjadi data pendukung dalam penelitian. Kemudian data tersebut dianalisis terhadap kenyataan sosial yang menjadi fokus penelitian.

Tujuan penggunaan metode lebih dari satu yaitu digunakan sebagai sarana pengembangan instrumen dalam riset; sebagai contoh hasil wawancara mendalam dalam riset kualitatif dan digunakan sebagai materi pertanyaan-pertanyaan dalam kuisioner pada riset kuantitatif.

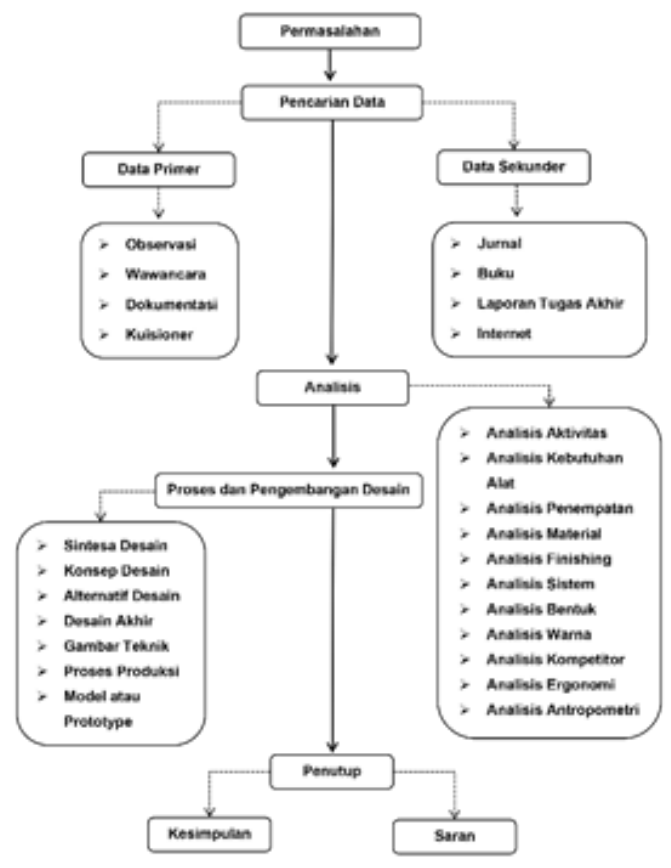

Gambar 1. Skema Penelitian

\section{Pembahasan \\ 4.1. Studi Kasus}

Studi kasus dilakukan oleh peneliti pada tailor sebab penelitian ini membutuhkan informasi mengenai workstation yang digunakan oleh para penjahit busana. Kegiatan studi kasus objek dilakukan di daerah Surabaya dan Sidoarjo yaitu di BONANZA Tailor dan Jaya International Tailor.

BONANZA Tailor bergerak dibidang jasa jahit busana yang berlokasi di Jl. Raya Prapen 43 Surabaya. Pada BONANZA Tailor terdapat ruang untuk display busana dan ruang untuk workstation yang terpisah, dimana ruang display busana beserta penerima customer berada di lantai 1 sedangkan untuk ruang produksi berada di lantai 2, untuk ukuran ruang kerja yang digunakan BONANZA Tailor ini adalah 6 x 6 $\mathrm{m}^{2}$.

Sedangkan Jaya International Tailor bergerak dibidang jasa jahit busana yang berlokasi Jl. Raya Suko Legok No.53, Sidoarjo. Pada Jaya International Tailor terdapat memiliki ruang produksi dengan ukuran 7 x $12 \mathrm{~m}^{2}$. Untuk Jaya International Tailor ruang penerimaan customer, produksi, dan display terdapat di lantai 1 .

\subsection{Studi Observasi Aktivitas}

Pada studi observasi aktivitas ini bertujuan untuk mengetahui aktivitas dari para pekerja mulai dari penerimaan customer hingga finishing busana. Dari kegiatan observasi yang dilakukan didapatkan data sebagai berikut:

Aktivitas pertama dalam menyetrika yang dilakukan oleh penjahit yaitu pengukuran badan customer membutuhkan beberapa peralatan seperti 1) Meteran jahit, 2) Bolpoint, 3) Kertas. Kemudian pembuatan pola pada kain dan pemotongan kain membutuhkan beberapa peralatan seperti 1) Penggaris jahit, 2) Kapur jahit, 3) Gunting kain.

Apabila pesanan berupa kebaya, setelah pemotongan pola maka harus disambung dengan jahitan dasar menggunakan 
Ni’matul Isnaini, Faza Wahmuda, Pengembangan Desain Worksation Untuk Penjahit

Busana Dengan Area Terbatas

jahitan tangan agar kain brokat dengan kain furing tetap sesuai dengan pola. Pada penyambungan kain dasar membutuhkan beberapa peralatan seperti 1) Jarum pentul, 2) Jarum jahit, 3) Benang.

Selanjutnya penyambungan kain menggunakan mesin jahit. Pada proses menjahit membutuhkan beberapa peralatan seperti 1) Mesin jahit, 2) Benang jahit, 3) Spul mesin jahit, 4) Gunting benang, 5) Gunting kain, 6) Meteran jahit.

Setelah penggabungan pola-pola pada kain, selanjutnya melakukan pemotongan bagian samping kain agar lebih rapih menggunakan mesin obras. Pada proses obras membutuhkan beberapa peralatan seperti 1) Mesin obras, 2) Benang obras, 3) Gunting benang. Pada pemasangan resleting pada baju membutuhkan beberapa peralatan seperti 1) Mesin jahit, 2) Spul mesin jahit, 3) Benang jahit, 4) Gunting benang, 5) Resleting.

Setelah baju sudah jadi lakukan penggosokan baju menggunakan setrika agar baju tidak kusut. Pada proses penggosokan baju membutuhkan beberapa peralatan seperti 1) Setrika, 2) Pelicin atau pewangi pakaian.

\subsection{Analisis Kebutuhan Kerja}

Analisis ini dilakukan untuk mengetahui kebutuhan dari aktivitas kerja yang dikelompokkan berdasarkan pembagian kerja yang dilakukan oleh para penjahit. Berikut adalah detail kegiatan beserta alatalat yang terlibat dalam kegiatan tersebut:

\section{A. Pembuatan dan Pemotongan Pola pada Kain}

1) Meteran jahit, 2) Bulpoin, 3) Buku nota, 4) Kain, 5) Penggaris jahit, 6) Kapur kain, 7) Gunting kain, 8) Gunting benang, 9) Jarum pentul, 10) Jarum jahit, 11) Benang jahit

\section{B. Proses Menjahit dan Obras}

1) Mesin jahit portable, 2) Mesin obras,

3) Benang jahit, 4) Benang obras, 5) Spul mesin jahit, 6) Gunting benang, 7)
Gunting kain, 8) Pendedel benang, 9)

Resleting, 10) Kancing

\section{Proses Setrika}

Pada proses penggosokan baju diperlukan meja khusus dengan penambahan alas rata yang diberi kai $\mathrm{n}$ agar pakaian tidak rusak.

\subsection{Analisis Kebutuhan Penyimpanan}

Analisis ini dilakukan untuk mengetahui kebutuhan penyimpanan dari peralatan dan perlengkapan menjahit dengan berdasarkan kebutuhan yang sering digunakan oleh para penjahit. Berikut adalah detail kebutuhan penyimpanan yang diperlukan dalam setiap kegiatan:

\section{A. Pembuatan dan Pemotongan Pola pada Kain}

Dibutuhkan penyimpanan yang berbeda pada kebutuhan pada aktivitas pembuatan dan pemotongan pola pada kain dengan penjahitan dasar. Untuk penyimpanan pada peralatan pembuatan pola antaralain : 1) Bulpoin, 2) Buku nota, 3) Penggaris jahit, 4) Kapur kain Untuk penyimpanan kain perlu dibedakan sendiri karena membutuhkan dimensi yang lebih besar.

\section{B. Proses Menjahit dan Obras}

Perlu penyimpanan khusus untuk benang dan spul mesin jahit karena kebutuhan benang yang beragam dalam segi jenis benang dan warna benang. Perlu penyimpanan khusus untuk resleting dan kancing karena kebutuhan yang beragam dalam segi jenis dan warna.

Untuk penyimpanan pada peralatan proses menjahit antaralain : 1) Gunting benang, 2) Gunting kain, 3) Pendedel benang, 4) Meteran jahit, 5) Jarum pentul, 6) Jarum jahit

\section{Proses Setrika}

Perlu penyimpanan khusus untuk setrika beserta pewangi pakaiannya. 
Vol. 7, No. 2, April 2020

\subsection{Analisis Dimensi Penyimpanan}

Analisis ini dilakukan untuk mengetahui dimensi dari penyimpanan kebutuhan berdasarkan pembagian kerja dan jumlah peralatan yang digunakan oleh para penjahit. Berikut adalah dimensi penyimpanan yang diperlukan:

\section{A. Pembuatan dan Pemotongan Pola pada Kain}

Untuk penyimpanan pada area kerja pembuatan dan pemotongan pola pada kain dapat diperkirakan memiliki dimensi 40 x 22 x $10 \mathrm{~cm}$. Kemudian untuk penyimpanan kain menyesuaikan dengan dimensi area kerja pembuatan dan pemotongan pola pada kain.

\section{B. Proses Menjahit dan Obras}

Untuk penyimpanan peralatan menjahit dapat diperkirakan memiliki dimensi $25 \times 20 \times 10 \mathrm{~cm}$, untuk penyimpanan benang jahit dan benang obras dapat diperkirakan memiliki dimensi $100 \mathrm{x}$ $10 \times 10 \mathrm{~cm}$, untuk penyimpanan spul mesin jahit dapat diperkirakan memiliki dimensi $40 \times 10 \times 10 \mathrm{~cm}$, dan untuk penyimpanan resleting dan kancing dapat diperkirakan memiliki dimensi 25 $\mathrm{x} 20 \mathrm{x} 10 \mathrm{~cm}$.

\section{Proses Setrika}

Untuk penyimpanan setrika dan pewangi dapat diperkirakan memiliki dimensi $30 \times 20 \times 15 \mathrm{~cm}$.

\subsection{Analisis Dimensi Area Kerja}

Analisis dimensi area kerja dilakukan untuk mengetahui detail dimensi workstation untuk penjahit busana yang didapatkan dari studi literatur dan disesuaikan dengan kebutuhan. Maka untuk dimensi produk dapat dibagi menurut pembagian kerja, berikut adalah dimensi setiap area kerja :

\section{A. Pembuatan dan Pemotongan Pola pada Kain}

Dibutuhkan permukaan yang luas, maka dimensi area kerja pembuatan dan pemotongan pola lebih panjang dari area kerja menjahit dan area kerja setri- ka. Maka didapatkan kesimpulan untuk dimensi panjang area kerja pembuatan dan pemotongan pola yaitu $152,4 \times 76,2$ $\mathrm{x} 100 \mathrm{~cm}$.

\section{B. Proses Menjahit dan Obras}

Untuk area kerja menjahit perlu penggabungan dengan aktivitas obras, karena kebutuhan area kerja yang sama dan menghemat ruang. Maka didapatkan kesimpulan untuk dimensi panjang area kerja menjahit yaitu $150 \times 55,9 \times 76,2$ $\mathrm{cm}$ untuk dimensi panjang terdapat tambahan sekitar $30 \mathrm{~cm}$ untuk jarak antara aktivitas menjahit dengan aktivitas obras.

\section{Proses Setrika}

Untuk area kerja setrika dapat menggunakan ukuran standart yang digunakan sama dengan area kerja menjahit karena tidak membutuhkan permukaan yang terlalu luas dan area kerja setrika hanya digunakan untuk setrika saja. Maka didapatkan kesimpulan untuk dimensi panjang area kerja menjahit yaitu 72,6 $\mathrm{x} 45,7 \times 76,2 \mathrm{~cm}$.

\subsection{Analisis Layout Area Kerja}

Analisis ini dilakukan untuk mengetahui kebutuhan penempatan berdasarkan hasil analisis kebutuhan penyimpanan. Analisis penempatan dapat dibedakan menjadi dua yaitu berdasarkan pembagian kerja dan berdasarkan kebutuhan yang sering digunakan. Berdasarkan pembagian kerja, maka desain workstation untuk penjahit busana terbagi menjadi beberapa bagian, yaitu meja pembuatan dan pemotongan pola, meja menjahit, meja obras, dan meja setrika. Berikut adalah layout area kerja penjahit busana : 
Ni’matul Isnaini, Faza Wahmuda, Pengembangan Desain Worksation Untuk Penjahit Busana Dengan Area Terbatas

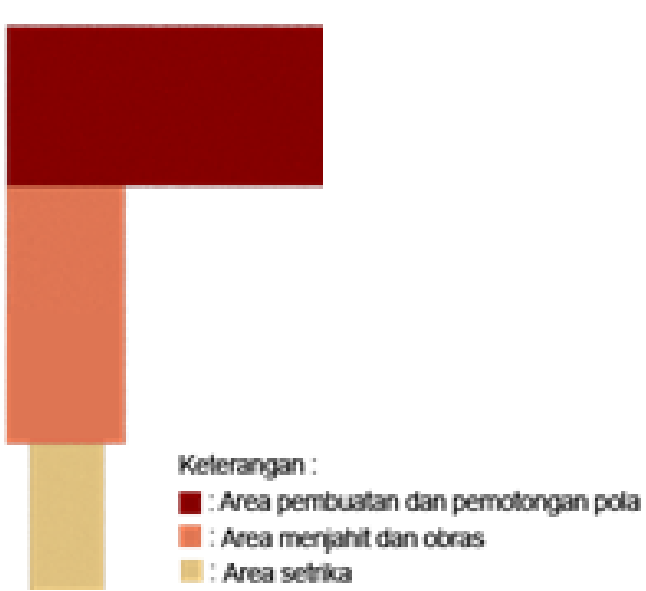

Gambar 2. Layout area kerja penjahit

\subsection{Analisis Penempatan}

Analisis penempatan berdasarkan kebutuhan yang sering digunakan, maka desain workstation untuk penjahit busana terbagi menjadi beberapa bagian, yaitu tempat benang, penyimpanan peralatan pembuatan pola, penyimpanan peralatan jahit, dan penyimpanan setrika. Berikut adalah matriks penempatan berdasarkan kebutuhan yang sering digunakan oleh penjahit busana.

Dari matriks dalam tabel 1 penempatan tersebut maka didapatkan alternatif penempatan sesuai dengan penyimpanan yang dibutuhkan. Berikut adalah alternative penempatan yang sesuai berdasarkan kebutuhan yang sering digunakan

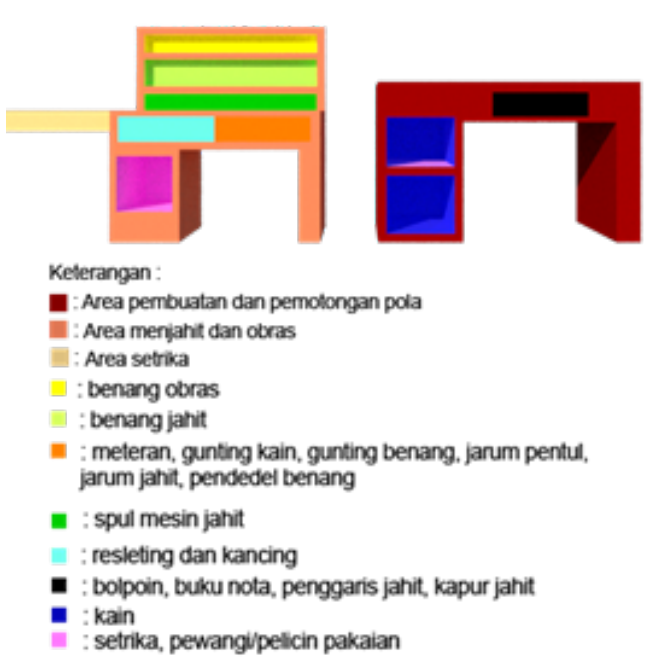

Gambar 3. Penempatan berdasarkan kebutuhan yang sering digunakan

\subsection{Analisis Material}

Analisis material dilakukan agar dapat menemukan material yang tepat untuk diaplikasikan pada produk. Berikut adalah kebutuhan material yang ditujukan untuk workstation untuk penjahit busana adalah 1) Permukaan yang rata dan halus, 2) Dapat menahan beban mesin jahit, 3) Dapat diaplikasikan untuk penyimpanan, 4) Material yang ringan, 5) Tidak mudah lapuk, 6) Harga murah.

Berdasarkan hasil analisis yang telah dilakukan peneliti, material utama yang digunakan pada redesain workstation untuk penjahit busana yaitu material kayu lapis/plywood karena material tersebut paling banyak memenuhi kriteria dari kebutuhan penjahit, kemudian material pendukung seperti alas untuk pembuatan dan pemotongan pola pada kain menggunakan akrilik dan alas untuk setrika menggunakan busa dan kain.

\subsection{Analisis Finishing}

Analisis finishing dilakukan agar dapat menemukan finishing yang tepat untuk diaplikasikan pada material pada produk. Berikut adalah kebutuhan finishing yang ditujukan untuk workstation untuk penjahit busana adalah 1) Permukaan yang rata dan halus, 2) Tidak mudah tergores, 3) 
Vol. 7, No. 2, April 2020

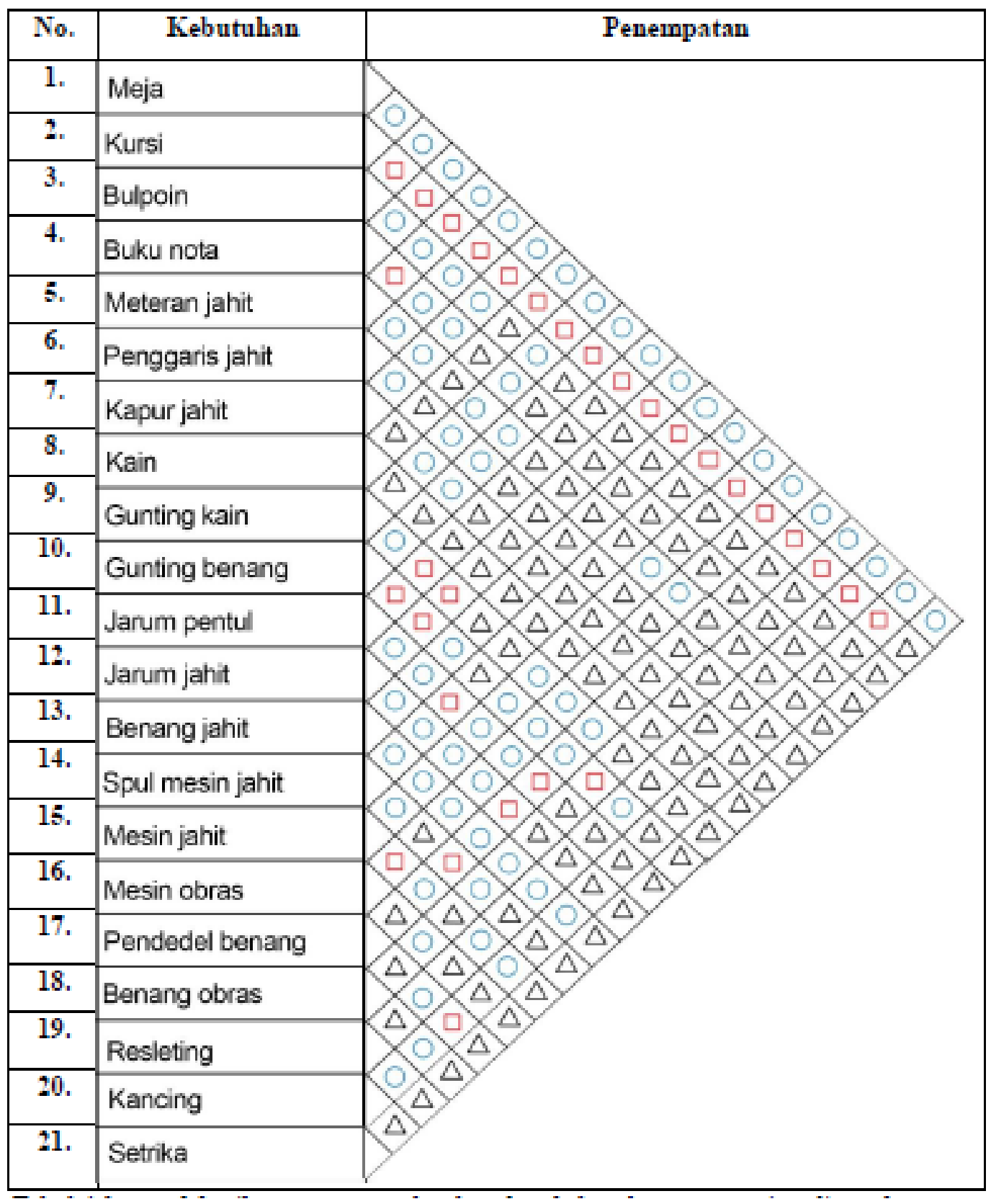

Tabel 1. Matriks penempatan berdasarkan kebutuhan yang sering digunakan 
Terlihat mewah, 4) Banyak macam warna, 5) Mudah dibersihkan, 6) Tahan lama, 7) Harga murah.

Berdasarkan hasil analisis yang telah dilakukan peneliti, finishing yang sesuai untuk workstation untuk penjahit busana adalah HPL (High Pressure Laminate).

\subsection{Analisis Sistem}

Analisis sistem dilakukan agar dapat menemukan sistem yang tepat untuk diaplikasikan pada pada produk. Berikut adalah kebutuhan sistem yang ditujukan untuk workstation untuk penjahit busana adalah 1) Ringkas dan efisien, 2) Terdapat penyimpanan peralatan jahit, 3) Penggabungan kegiatan yang berbeda dalam satu workstation.

Berdasarkan hasil analisis yang telah dilakukan peneliti, sistem yang sesuai untuk workstation untuk penjahit busana adalah 1) Folding, sistem folding digunakan untuk meja setrika. 2) Rel Sliding, sistem rel sliding digunakan pada laci tempat penyimpanan peralatan dan perlengkapan menjahit, dapat juga sebagai opsi untuk sistem pada meja setrika.

\subsection{Analisis Bentuk}

Analisis bentuk digunakan untuk memilih bentuk jenis apa yang akan diaplikasikan pada produk. Bentuk yang akan diaplikasikan untuk redesain workstation untuk penjahit busana adalah persegi panjang untuk meja menjahit dan pemotongan pola karena dibutuhkannya alas yang lebih luas daripada bentuk persegi, kemudian untuk meja setrika dapat menggunakan bentuk kombinasi dari persegi panjang dan lingkaran karena persegi memiliki bentuk yang mudah ditata dengan tambahan variasi dari lingkaran.

\subsection{Analisis Warna}

Analisis warna dilakukan untuk menentukan warna apa yang akan diaplikasikan pada redesain workstation untuk penjahit busana. Berikut adalah kebutuhan warna yang ditujukan untuk workstation untuk penjahit busana adalah 1) Warna cerah dan memberi kesan bersih pada workstation, 2) Warna yang netral, 3) Warna yang membuat rileks saat bekerja.

Berdasarkan studi literatur mengenai karakteristik dan simbolis warna didapatkan warna putih, hijau dan abu-abu yang sesuai untuk diaplikasikan pada workstation untuk penjahit busana, karena warna-warna tersebut memenuhi dari kebutuhan penjahit.

\subsection{Sintesa Desain}

Dari analisis yang telah dilakukan, maka dapat disusun spesifikasi desain yang akan diterapkan pada produk adalah sebagai berikut.

\section{A. Pengelompokan Pembagian Kerja}

\begin{tabular}{|c|c|c|}
\hline $\begin{array}{l}\text { Kelompok } \\
\text { Area Kerja }\end{array}$ & $\begin{array}{c}\text { Dimensi } \\
\text { Penyimpanan } \\
\text { Alat } \\
\end{array}$ & $\begin{array}{c}\text { Dimensi } \\
\text { Area } \\
\text { Kerja } \\
\end{array}$ \\
\hline $\begin{array}{l}\text { Area Kerja } \\
\text { Pembuatan } \\
\text { dan } \\
\text { pemotongan } \\
\text { pola pada } \\
\text { kain }\end{array}$ & $\begin{array}{l}\text { 1. Penyimpanan } \\
\text { peralatan } \\
\text { pembuatan } \\
\text { dan } \\
\text { pemotongan } \\
\text { pola pada kain } \\
\text { (40x22x10cm) } \\
\text { 2. Penyimpanan } \\
\text { kain } \\
(40 \times 70 \times 40 \mathrm{~cm})\end{array}$ & $\begin{array}{l}150 \mathrm{x} 76 \mathrm{x} \\
100 \mathrm{~cm}\end{array}$ \\
\hline $\begin{array}{c}\text { Area Kerja } \\
\text { Menjahit dan } \\
\text { Obras }\end{array}$ & 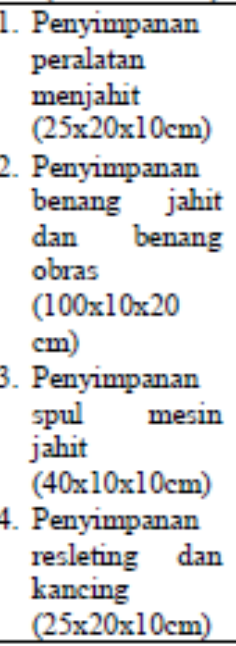 & $\begin{array}{l}150 \times 56 \mathrm{x} \\
76 \mathrm{~cm}\end{array}$ \\
\hline $\begin{array}{c}\text { Area Kerja } \\
\text { Setrika }\end{array}$ & $\begin{array}{l}\text { Penyimpanan } \\
\text { setrika dan } \\
\text { pewangi pakaian } \\
(30 \times 20 \times 20 \mathrm{~cm})\end{array}$ & $\begin{array}{l}75 \mathrm{x} 45 \mathrm{x} \\
73 \mathrm{~cm}\end{array}$ \\
\hline
\end{tabular}


Vol. 7, No. 2, April 2020

\section{B. Material}

Material utama yang akan digunakan redesain workstation untuk penjahit busana yaitu plywood/kayu lapis, kemudian untuk permukaan meja pembuatan dan pemotongan pola menggunakan kombinasi akrilik, sedangkan untuk permukaan meja setrika menggunakan kombinasi busa dan kain.

\section{Finishing}

Finishing yang diaplikasikan untuk redesain workstation untuk penjahit busana adalah HPL (High Pressure Laminate) untuk melapisi material plywood (kayu lapis).

\section{Sistem}

Sistem yang diaplikasikan untuk diaplikasikan pada redesain workstation untuk penjahit busana adalah : 1) Folding, sistem folding digunakan untuk meja setrika. 2) Rel Sliding, sistem rel sliding digunakan pada laci tempat penyimpanan peralatan dan perlengkapan menjahit, dapat juga sebagai opsi untuk sistem pada meja setrika.

\section{E. Bentuk}

Bentuk yang akan diaplikasikan untuk redesain workstation untuk penjahit busana adalah persegi panjang untuk meja menjahit dan pemotongan pola karena dibutuhkannya alas yang lebih luas daripada bentuk persegi, kemudian untuk meja setrika dapat menggunakan bentuk kombinasi dari persegi panjang dan lingkaran karena persegi memiliki bentuk yang mudah ditata dengan tambahan variasi dari lingkaran.

\section{F. Warna}

Warna yang akan diaplikasikan redesain workstation untuk penjahit busana adalah warna putih, hijau, dan abu-abu, untuk pembagian warna pada produk dapat disesuaikan dengan desain yang akan dibuat.

\subsection{Konsep Desain}

Konsep desain yang akan diaplikasikan pada produk workstation untuk penjahit busana adalah compact and clean design. Compact workstation adalah workstation yang mewadahi berbagai fungsi yang memiliki keterkaitan aktivitas ke dalam sebuah produk sehingga padat dan lebih rapi. Kemudian clean design yang dimaksud yaitu untuk penggunaan warna yang cerah, bentuk yang simple/sederhana sehingga membuat produk terlihat ringkas, rapi dan bersih.

\subsection{Alternatif Desain \\ 1. Alternatif Desain 1}

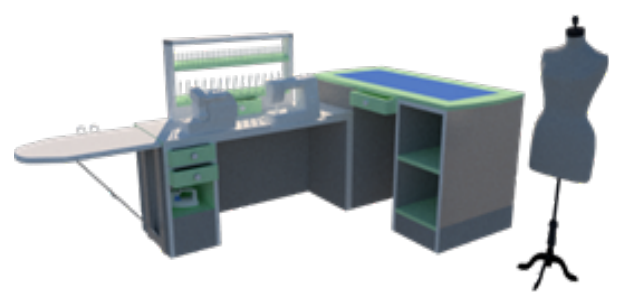

Gambar 4. Alternatif Desain 1

\section{Alternatif Desain 2}

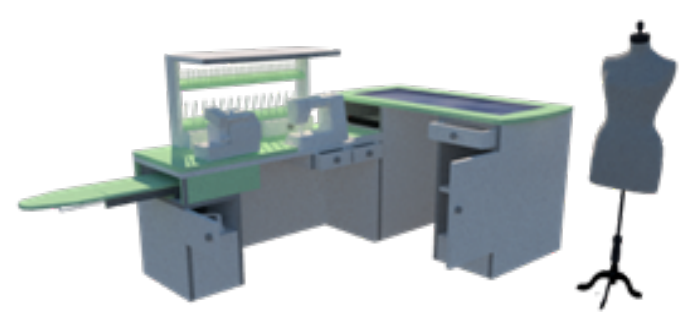

Gambar 5. Alternatif Desain 2

\section{Alternatif Desain 3}

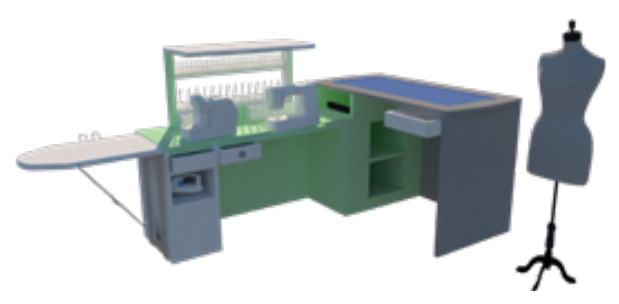

Gambar 6. Alternatif Desain 3 
Ni'matul Isnaini, Faza Wahmuda, Pengembangan Desain Worksation Untuk Penjahit Busana Dengan Area Terbatas

4. Alternatif Desain 4

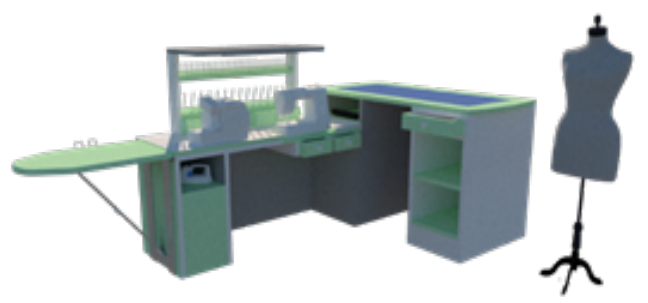

Gambar 7. Alternatif Desain 4

\section{Alternatif Desain 5}

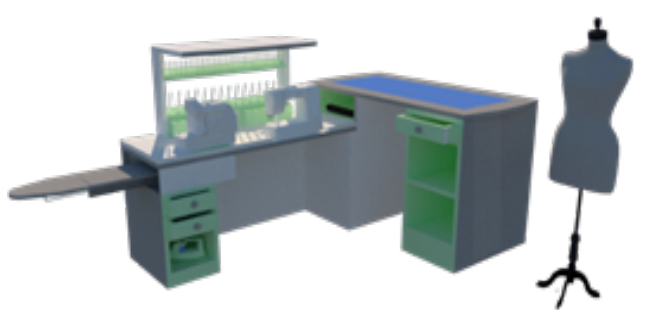

Gambar 8. Alternatif Desain 5

\subsection{Desain Terpilih}

Dari beberapa alternatif desain yang telah dibuat maka didapat desain final yang memiliki spesifikasi sesuai dengan sintesa desain yang didapat.

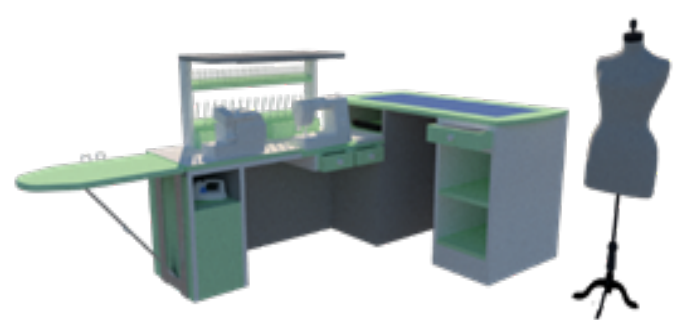

Gambar 9. Desain Terpilih

Desain yang terpilih yaitu alternatif desain ke 4, jika dilihat dari struktur penyangga pada area kerja setrika lebih kuat menggunakan sistem folding dengan engsel, kemudian pada workstation terdapat tambahan lampu pada atas area menjahit dan stop kontak untuk mesin jahit, dan terdapat kombinasi bentuk lingkaran pada area kerja pembuatan dan pemotongan pola pada kain.

\section{Kesimpulan dan Saran 5.1. Kesimpulan}

Redesain workstation untuk penjahit busana bertujuan untuk mempermudah dalam proses menjahit, yaitu pada workstation yang tidak hanya berfungsi untuk menjahit saja tetapi juga untuk pembuatan dan pemotongan pola, obras, dan menjahit serta dilengkapi dengan penyimpanan semua peralatan dalam menjahit. Penjahit pada awalnya menggunakan meja sederhana dengan tempat penyimpanan peralatan yang seadanya akan terbantu dengan adanya perancangan produk ini, yang bertujuan memenuhi kegiatan dalam tiga akivitas yang dilakukan oleh penjahit.

\subsection{Saran}

Penelitian redesain workstation untuk penjahit busana ini masih memiliki banyak kekurangan, diantaranya yaitu perlu dilakukan lebih banyak lagi penelitian mengenai dimensi penyimpanan peralatan dan dimensi produk yang sesuai dengan aktivitas yang dikerjakan. Hal tersebut dikarenakan karena tidak adanya ketetapan dimensi produk yang ditujukan untuk aktivitas yang dikerjakan seperti pembuatan dan pemotongan pola. Oleh karena itu, diharapkan selanjutnya dapat lebih menyempurnakan kekurangan yang dimiliki pada penelitian ini 
Vol. 7, No. 2, April 2020

\section{Daftar Pustaka}

Sarwono, Jonatan. 2011. Mix Methods; Cara Menggabungkan RIset Kuantitatif dan Riset Kualitatif Secara Benar. Jakarta : PT. Elex Media Komputindo

Sugiyono. 2011. Metode Penelitian Kuantitatif, Kualitatif, dan R\&D. Bandung : Afabeta

Ariyani, Resti. 2013. Potensi Usaha Penjahit Pakaian dalam Meningkatkan Pendapatan Keluarga Menurut Ekonomi Islam (Studi Kasus Penjahit Pakaian Di Kecamatan Kuok). Skripsi. Program S1 Fakultas Syariah dan Ilmu Hukum. Universitas Islam Negeri Sultan Syarif Kasim. Riau.

Sugiyono. 2015. Metode Penelitian Kombinasi (MixMethods). Bandung : Afabeta $\neg \neg \neg \_.$_2015. Arti kata Clean di KBBI. Dalam https://lektur.id/arti-clean/. Diakses pada 12 Desember 2019.

Goutama, Yunivia Anggoro. 2017. "HANG-A ROOM DAN LEAF LIFE” PRODUK INTERIOR COMPACT UNTUK PRODUKTIVITAS.” Simposium Nasional RAPI XVI. 